THE RESEARCH INSTITUTE OF INDUSTRIAL ECONOMICS

WORKING PAPER No. 479, 1997

\title{
INTERNAL EFFICIENCY AND EXTERNAL CONDITIONS
}

BY JÖRGEN W. WEIBULL 


\title{
INTERNAL EFFICIENCY AND EXTERNAL CONDITIONS
}

\author{
JÖRGEN W. WEIBULL*
}

May 7, 1997

\begin{abstract}
This paper develops a new analytical approach to the old question whether market conditions may influence the internal efficiency of firms. The basic textbook model of the firm is slightly extended to incorporate managers' incentives to reduce production costs in an imperfectly competitive product market. This is done without invoking any agency problem or other form of information asymmetry. The analysis extends Marshallian and Hicksian consumer analysis to managers' demand for leisure in imperfectly competitive environments with a fixed number of firms, and free entry, respectively. Conditions are identified under which product market integration enhances the internal efficiency of firms, and it is shown that market integration is Pareto improving under free entry.
\end{abstract}

This is a revised version of Weibull [19]. I am grateful for helpful comments to various drafts from Avinash Dixit, Bengt Holmström, Henrik Horn, Yeongjae Kang, Johan Lagerlöf, Assar Lindbeck, Jim Markusen, Massimo Motta, Roy Radner, Jean Tirole, and Tony Venables. This research was supported by the IUI (the Research Institute of Industrial Economics), Stockholm, Sweden. 


\section{INTRODUCTION}

Policy discussions concerning internal efficiency and competition frequently presume that market integration enhances the internal efficiency of the participating firms. In fact, this is one of the arguments advocated in favor of the European union. The European commission writes that "...the new competitive pressures brought about by the completion of the internal market can be expected to ... produce appreciable gains in internal efficiency ..." ([2], p.126). Such a view indeed has support from certain major classics: "... good management, ... can never be universally established but in consequence of the free and universal competition which forces every body to have recourse to it for the sake of self-defence..." (Adam Smith [17], pp. 163-164).

By contrast, current standard microeconomics text-book treatments do not deal with this issue: all firms by assumption operate at maximal internal efficiency, irrespective of market conditions. A monopoly firm is internally just as efficiently organized as is a firm in an oligopolistic or perfectly competitive market. However, recent theoretical studies of this issue have shown that if the basic model of the firm is expanded to include an agency problem then market conditions may indeed influence the internal efficiency of a firm. More specifically, the incentive power of equilibrium contracts between owners and management may depend on external market conditions. As a result, managerial efforts to improve the internal efficiency of the firm may change when market conditions change, though not always in the expected direction, see Holmström [8], Hart [3], Nalebuff and Stiglitz [13], Scharfstein [15], Hermalin [6], Martin [12], Horn, Lang and Lundgren [9], and Schmidt [16].

The term "internal efficiency" used in this literature is perhaps unfortunate, and was originally kept undefined. In his seminal paper on this topic, Leibenstein [10] avoided to give a definition but introduced the term $X$-inefficiency. Broadly speaking, the terms "internal efficiency" and "X-efficiency" were used much in the same way as the layman would use the term "good management." Here these terms will be understood in the narrow sense of "low production costs." A firm that operates at a lower cost at all output levels than another firm will be called "internally more efficient." In particular, "internal efficiency" has little, if anything, to do with Pareto efficiency (since it neglects welfare effects on managers).

In contrast to the cited information-based approaches, the present study takes the viewpoint that market conditions may influence managers' incentives to improve internal efficiency even in the absence of agency problems. In order to study this possibility in its purest form we thus assume that firms are managed by their owners. Such managers care about profits, but they may also have preferences concerning the effort they put into their firm. An owner who operates his or her own firm may 
thus face a trade-off between profits and leisure - taken to be the opposite of effort. ${ }^{1}$ Exerting more managerial effort - more intense work, longer hours in the office, or less pleasant decisions (such as firing staff) - the owner-cum-manager may improve the firm's internal efficiency and thereby its profits. Moreover, this trade-off may depend on market conditions. For instance, under stiffer competition, equilibrium profits may be lower, and the marginal return to increased effort on profit may or may not be higher. The income effect on managerial effort is unambiguously positive in such circumstances if leisure is a normal good. As sir John Hicks put it: "The best of all monopoly profits is the quiet life." (Hicks [7], p. 8). However, the total effect also depends on the substitution effect, and, of course, on what exactly is meant by "stiffer competition." In particular, reduction of barriers to entry involves one form of "stiffened competition" while market integration involves another form of "stiffened competition." Income and substitution effects of trade barriers on managerial incentives, in markets where all firms are price takers, have been studied in Corden [1] and J. Martin [11]. The present approach can be viewed as an extension of Martin's model to imperfectly competitive markets with and without barriers to entry. The income effect on managerial effort is studied in the context of an agency model in Hermalin [6].

In terms of analytical tools, the present paper suggests a minor extension of the basic microeconomics text-book model of the firm, perhaps the slightest extension that includes managerial effort as a non-traded input. More exactly, instead of treating a firm's production possibilities as exogenous (and known) to every manager, we here endogenize the production possibility set of a firm by letting it in part depend on its manager's efforts. ${ }^{2}$ The more such efforts the manager makes, the more production opportunities become available to the firm. Indeed, it may be argued that an essential part of management's task is precisely to identify production possibilities available to the firm. This view was advocated by Hayek, who saw economic agent's acquisition of knowledge as a fundamental aspect of an economy: "... knowledge ... is not given to anyone in its totality..." (Hayek [4], p.321), "it is only through the process of competition that the facts will be discovered" (Hayek [5], p.96).

Leibenstein's [10] treatment was essentially informal and empirical. On the basis of his empirical studies he claimed that "The simple fact is that neither individuals nor firms work as hard, nor do they search for information as effectively, as they could. The importance of motivation and its association with degree of effort and search arises because the relation between inputs and outputs is not a determinate one." ( $p$.

\footnotetext{
${ }^{1}$ We will neglect the realistic possibility that managers may associate positive utility with some positive levels of effort. However, a generalization in this direction does not seem difficult.

${ }^{2}$ For the sake of simplicity it is here assumed that all managers are equally able.
} 
407). He claimed that a significant part of the beneficial effects of competition come about via increased internal efficiency of firms (X-efficiency): "The data suggest that cost reduction that is essentially a result of improvement in $X$-efficiency is likely to be an important component of the observed residual in economic growth." (p. 408). "Thus we have instances where competitive pressures from other firms or adversity lead to efforts toward cost reduction, and the absence of such pressures tends to cause costs to rise." (pp. 408-409).

The present analysis is performed in a simple formal model, restricted to the case of a Cournot market for a homogenous product, and focuses on two polar cases: (a) a given set of firms in the market, and (b) free entry to and exit from the market. When the set of firms is fixed all managers simultaneously choose their levels of managerial effort. In the case of free entry we imagine a large population of potential entrepreneurs, each of whom first decides whether or not to set up a firm, and thereby become its owner-cum-manager, in the studied product market. All entrepreneurs have access to all production factors and inputs, at fixed and given prices. As an alternative to setting up a firm, each entrepreneur has some (unmodeled) outside option. Once the entry decisions have been taken, these decisions become known to all entrants, and these simultaneously choose their levels of managerial effort - just as in the case of a given set of firms. The analysis presumes identical entrepreneurs/managers, and is focused on symmetric market equilibria.

It turns out that the comparative statics analysis of how managers adapt their efforts to changed market conditions is formally parallel to classical models of the price-taking consumer. In the case of a fixed set of firms in the market the analysis is similar to the Marshallian demand analysis, while under free entry it takes the form of Hicksian demand analysis. In the first case, changed market conditions induce an income and a substitution effect on managers' efforts, while in the second case managers are kept at their reservation utility level (the income effect on their effort is "compensated"). In both cases there is a major difference in comparison with classical consumer demand analysis. Instead of a non-strategic environment (price-taking consumers) we here have a strategic environment (the price of leisure is influenced by each manager's action).

Conditions are identified under which an increased number of firms in a given market induces managers to exert more effort. Hence, stiffer competition so defined leads to increased internal efficiency (lower unit cost of production). A central concern of this study is whether market integration (or trade liberalization) induces higher internal efficiency. The thought-experiment is simple: put together two markets - "countries" - that were before completely isolated from each other. Conditions are identified under which such a change in external conditions results in increased internal efficiency, both when the number of firms per market (country) is fixed and 
unaffected by the change, and when there is free entry and exit of firms before and after the integration.

In both cases, consumers benefit more from trade than in the standard Cournot model: to the pressure on the market price from an increased number of competitors is added the effect from reduced production costs in each firm. According to Leibenstein [10] the second effect is empirically much stronger than the former. Including the welfare effect on entrepreneurs, the net welfare effect of market integration under free entry is unambiguous: consumers face a lower price of the product and all entrepreneurs remain at their reservation utility level. Market integration is thus a Pareto improvement.

By adopting the present approach, which neglects informational problems, I do not suggest that such problems are unimportant for the questions at hand. On the contrary, such problems seem to be of fundamental importance. However, in the spirit of Occam's razor the present study seeks to find the simplest setting which allows for the possibility that market conditions influence the internal efficiency of firms. Richer and more complex models, such as those based on asymmetric information between owners and managers, can hopefully be more easily understood and appreciated against the background of such simpler models.

For a discussion of various concepts of efficiency and competition, and the interplay between these, see Vickers [18]. A recent empirical investigation of relations between competition and corporate performance is given in Nickell [14].

The paper is organized as follows. Section 2 presents the model and section 3 the analytical results. Numerical results for a parametric special case are given in Section 4, which also contrast Marshallian demand analysis with Hicksian demand analysis of managers' decisions. Section 5 concludes with a brief discussion of some potential extensions. Mathematical proofs are not included; they are provided in a companion working paper, Weibull [19].

\section{THE MODEL}

The model is developed in two steps. First, the set of firms participating in the product market in question is taken to be fixed and given. Then entry and exit decisions are introduced. In other words, we first study a "post-entry" subgame of a larger game, then the full game.

2.1. The demand side. Consider a Cournot product market for a homogeneous good, with $n$ identical firms. The market price $p$ is determined by an inverse demand function, $p=P_{m}(Q)$, where $Q$ is aggregate output, $Q=\sum_{j=1}^{n} q_{j}$. Here $m$ is an exogenous parameter that will be interpreted as the number of (identical) countries in a free-trade area for the good in question. With linear demand in each country, 
$D(p)=1-p$, and in the absence of transportation costs, aggregate demand in the free-trade area is $m D(p)=m-m p$. Motivated by this example, the following assumption will be maintained throughout the analysis:

$$
P_{m}(Q) \equiv 1-Q / m
$$

where $m>0$.

2.2. Production costs and managerial effort. Each firm is managed by its owner. The key assumption in this study is that managerial efforts can reduce the firm's production costs. The channel from managerial effort to production cost is thought to go via the firm's production possibility set, or, equivalently, via its family of input requirement sets (one for each output quantity). Here it is assumed that the manager can expand the input requirement set associated with any given output level by exerting more managerial effort. Formally, if $V(q, e)$ is the input requirement set associated with output level $q$ when the manager exerts effort $e$, then the total cost to produce $q$ is

$$
C(q, w, e)=\min _{z \in V(q, e)} w \cdot z
$$

where $w$ is the price vector for inputs. The assumption that the manager can expand the input requirement set can be formally stated as: $e<e^{\prime} \Rightarrow V(q, e) \subset V\left(q, e^{\prime}\right) \forall q{ }^{3}$ It follows from (2) that the production $\operatorname{cost} C(q, w, e)$ is non-increasing in managerial effort $e .^{4}$

For the sake of analytical simplicity, the subsequent analysis will be focused on the special case when there is no fixed cost, and, at any given level of managerial effort, the firm's unit (or marginal) cost is constant. This unit cost is assumed to be continuously decreasing in managerial effort at a non-increasing rate. The domain of the effort variable is normalized to the unit interval, and the price vector $w$ is notationally suppressed (since this will be held constant):

(A) $C(q, e) \equiv c(e) q$, where $c:[0,1] \rightarrow[0,1]$ is a twice continuously differentiable function with $c^{\prime}<0, c^{\prime \prime} \geq 0, c(0)=1$ and $c(1)=0$.

\footnotetext{
${ }^{3}$ Equivalently: more managerial effort increases the production possibility set $Y$ of "netput" vectors: $e<e^{\prime} \Rightarrow Y(e) \subset Y\left(e^{\prime}\right)$.

${ }^{4}$ Cost-reducing managerial effort can also be concerned with adaptation to fluctuating input prices, market conditions, or tax rules. Alternatively, managers may exhibit bounded rationality when they seek a cost-minimizing input vector in a known input requirement set. More effort may then lead to less excessive cost (over the minimum cost).
} 
The assumption of a constant unit cost holds if production exhibits constant returns-to-scale (CRS) in non-managerial inputs.

When aggregate output is $Q$, price is $p=1-Q / m$, by equation (1). Subtracting production costs from revenues, we obtain the following expression for the profit to firm $i$ :

$$
\pi_{i}=\left[1-\frac{Q}{m}-c\left(e_{i}\right)\right] q_{i}
$$

2.3. Managers' preferences. The manager of each firm derives utility $u(\pi, e)$ from her firm's profit $\pi$ and her managerial effort $e$. The analysis is restricted to utility functions of the following separable form: ${ }^{5}$

(B) $u(\pi, e) \equiv \varphi(\pi)-\psi(e)$, where

(B1) $\varphi: \mathbb{R} \rightarrow \mathbb{R} \cup\{-\infty\}$ is twice differentiable on $\mathbb{R}_{++}$with $\varphi^{\prime}>0$ and relative risk aversion $r_{\varphi}>\frac{1}{2}$, and $\varphi(\pi)=-\infty$ for $\pi \leq 0$,

(B2) $\psi:[0,1) \rightarrow \mathbb{R}$ is twice differentiable, $\psi^{\prime}, \psi^{\prime \prime}>0, \psi(0)=\psi^{\prime}(0)=0$, and $\lim _{e \rightarrow 1} \psi(e)=+\infty$.

Hence, a manager's utility is increasing in her firm's profit. This is the case if the manager receives a monetary reward that is an increasing function of her firm's profit, granted she does not consume the product in the studied market (the price of which is endogenous). Moreover, the marginal utility of profit, $\varphi^{\prime}$, is decreasing at a rate that is sufficiently high to keep the relative risk aversion of the subutility function $\varphi$ above one half. The disutility of managerial effort increases with effort, from zero to plus infinity, as effort goes from its lower to its upper bound. Also the marginal disutility of effort is increasing with effort.

2.4. Solution concepts. The interaction between the $n$ managers in the product market is modeled as a simultaneous-move game in which each manager $i$ chooses a combination $\left(e_{i}, q_{i}\right)$ of effort and output in order to maximize her utility $u\left(\pi_{i}, e_{i}\right)$. The focus will be on symmetric Nash equilibria, i.e., Nash equilibria in which all participating managers choose the same output $q$ and the same effort $e$.

In the case of free entry and exit such product market interaction will be embedded as a "post entry" subgame of a larger game that involves an "entry stage" in which the number of participating firms is determined endogenously. We then imagine an infinite population of identical entrepreneurs, each of whom may set up a firm become an owner-cum-manager - in the product market in question. The alternative

\footnotetext{
${ }^{5}$ The relative risk aversion $r_{\varphi}$ of the subutility function $\varphi$ is defined by $r_{\varphi}(\pi)=-\pi \varphi^{\prime \prime}(\pi) / \varphi^{\prime}(\pi)$.
} 
is to take some outside option that yields utility $\bar{u} \in \mathbb{R}$. The equilibrium number of participating firms, $n$, will be treated as a real, rather than integer, variable. Consequently, the equilibrium utility to all entrepreneurs, those who enter and those who stay out, is the same, $\bar{u}$.

\section{ANALYSIS}

It turns out to be analytically convenient to make a transformation of variables before one embarks on such an analysis. Instead of using each managers effort $e_{i}$ as a decision variable, we will use her effective effort, defined as $x_{i}=1-c\left(e_{i}\right)$. By condition (A), there is a one-to-one relation between $e_{i}$ and $x_{i}$, such that $x_{i}$ is strictly increasing from zero to one as $e_{i}$ increases from zero to one. Hence, it is decision-theoretically (and strategically) immaterial if we use $e_{i}$ or $x_{i}$ as part of $i$ 's strategy. For later notational convenience we will write $b$ for the inverse $c^{-1}$ to the unit-cost function $c{ }^{6}$ Hence $e_{i}=b\left(1-x_{i}\right)$, where $b(0)=1, b(1)=0, b^{\prime}<0$ and $b^{\prime \prime} \geq 0$, by condition (A). ${ }^{7}$

Conditions (A) and (B) will be assumed to hold throughout this section.

3.1. Given set of firms in the market. As mentioned above, the focus is here on symmetric Nash equilibrium in the interaction between the $n$ managers in the product market. Using the above transformation of variables, a strategy to manager $i$ is a pair $s_{i}=\left(x_{i}, q_{i}\right) \in(0,1) \times \mathbb{R}_{+}$, and the payoff to manager $i$, when a strategy profile $s=\left(s_{1}, \ldots, s_{n}\right)$ is played, is

$$
U_{i}(s)=\varphi\left[\left(x_{i}-\frac{1}{m} \sum_{j=1}^{n} q_{j}\right) q_{i}\right]-\psi\left[b\left(1-x_{i}\right)\right] .
$$

A strategy profile $s$ is symmetric if there exists a pair $(x, q) \in(0,1) \times \mathbb{R}_{+}$such that $s_{i}=(x, q)$ for all $i$. Such a pair $(x, q)$ is said to represent the profile $s$. A symmetric profile $s$ is interior if $q>0$. Note that a symmetric Nash equilibrium is necessarily interior. For if $q_{i}=0$, then no $x_{i} \in(0,1)$ is optimal: $U_{i}(s)=\varphi(0)-\psi\left[b\left(1-x_{i}\right)\right]$, a strictly decreasing function of $x_{i} \in(0,1)$.

A necessary first-order condition for interior Nash equilibrium is, for each $i=$ $1, \ldots, n$ :

$$
\frac{\partial U_{i}(s)}{\partial q_{i}}=0 \quad \Leftrightarrow \quad q_{i}=\frac{1}{2}\left(m x_{i}-\sum_{j \neq i} q_{j}\right) .
$$

\footnotetext{
${ }^{6}$ The function $c$ is a bijection from the interval $[0,1]$ to itself.

${ }^{7}$ Differentiation of the identity $b(c(e)) \equiv e$ gives $b^{\prime}(c(e)) c^{\prime}(e) \equiv 1$. Thus $b^{\prime}<0$. Differentiation of the latter identity gives $b^{\prime \prime}(c(e))\left[c^{\prime}(e)\right]^{2}+b^{\prime}(c(e)) c^{\prime \prime}(e) \equiv 0$. Thus $b^{\prime \prime} \geq 0$.
} 
Hence, in a symmetric Nash equilibrium we necessarily have

$$
q=\frac{m x}{n+1}
$$

a formula familiar from the standard Cournot model with constant unit cost and linear demand. (Set $m=1$ and $x=1-c$.) This is not surprising: since profit has positive marginal utility to the manager, she should, at any effort level that she chooses, adapt her firm's output optimally to its unit (marginal) cost. In symmetric equilibrium all effort levels, and hence unit costs, are the same, and equation (6) results. This equation also shows that the more effort managers exert in a symmetric equilibrium, the more output will their firms produce. The exact relation between effort and output depends on market conditions, here represented by market size, $m$, and the number of firms, $n$. Market conditions matter.

Another necessary first-order condition for interior Nash equilibrium is, for each $i=1, \ldots, n$ :

$$
\frac{\partial U_{i}(s)}{\partial x_{i}}=0 \Leftrightarrow q_{i} \varphi^{\prime}\left[\left(x_{i}-\frac{1}{m} \sum_{j=1}^{n} q_{j}\right) q_{i}\right]+\psi^{\prime}\left[b\left(1-x_{i}\right)\right] b^{\prime}\left(1-x_{i}\right)=0 .
$$

Hence, in a symmetric equilibrium the following equation in one variable, the effective managerial effort $x$, holds (we have used (6)):

$$
\frac{m x}{n+1} \varphi^{\prime}\left[m\left(\frac{x}{n+1}\right)^{2}\right]+\psi^{\prime}[b(1-x)] b^{\prime}(1-x)=0
$$

Increased effort has a direct and an indirect effect on utility. The indirect effect comes about via the induced increase in profit, involving also optimal adaptation of output. The first term above represents this indirect effect of a marginal increase in effort, and the second term (negative) represents the direct effect. This equation plays a key role in the subsequent analysis.

It is not difficult to show that equation (8) has a unique solution $x^{*} \in(0,1)$. In view of this result the question arises whether the found pair $\left(x^{*}, q^{*}\right)$, with $q^{*}$ determined from $x^{*}$ in equation (6), indeed represents a Nash equilibrium. A sufficient condition for this to hold is that the resulting utility to a manager, $u\left(x^{*}, q^{*}\right)$, exceeds the utility she would obtain when producing zero and making no effort, $\varphi(0)-\psi(0)=$ $\varphi(0)$ : if $u\left(x^{*}, q^{*}\right)>\varphi(0)$, then there exists exactly one symmetric Nash equilibrium.

Equation (8) permits certain comparative statics observations. In particular, it is not difficult to show that its solution, the equilibrium level $x^{*}$ of effective managerial effort, rises with the number $n$ of firms. An increase in the number $n$ of firms reduces 
both the equilibrium profits per firm and the marginal return to effort. However, the income effect dominates the substitution effect:

Proposition 1. Equilibrium managerial effort is strictly increasing in the number $n$ of firms in a market of fixed size $m$.

Increased competition, in this specific sense, enhances firms' internal efficiency. This is, for example, the case if barriers to entry are reduced so that new firms enter the market. Deregulation and privatization policies may clearly have such effects.

When the number of firms in a market increases, then consumers benefit more from increased competition in the present model than they do in the standard Cournot model. On top of the usual beneficial consequence from a larger number of firms operating at given production costs, we here have an incentive effect inside firms that brings down production costs in each firm. Formally, the equilibrium market price, $p^{*}$, is given by a convex combination of the unit cost $c\left(e^{*}\right)$ and 1 :

$$
p^{*}=\frac{n}{n+1} c\left(e^{*}\right)+\frac{1}{n+1} .
$$

The weight to the unit cost is smaller the more firms there are in the market. ${ }^{8}$ Since the unit cost is less than one, the equilibrium price decreases when the number of firms increases, at any fixed level of managerial effort, and equilibrium effort rises, the unit cost $c\left(e^{*}\right)$ decreases with the number of firms in the market. Hence, the "standard" oligopolistic price effect from an increase in the number $n$ of firms is enhanced.

One would expect that managers' utility falls with an increase in the number of firms in the market. This follows readily from the above observations: manager's equilibrium utility, $v(n, m)$, is a continuous and strictly decreasing function of $n$ (at any given and fixed value of market size $m$ ). In view of the downward pressure from an increased number of firms on the market price we conclude that utility is transferred from managers to consumers as the number of firms in the market rises. ${ }^{9}$

3.2. Free entry and exit. In equilibrium in the full entry game no active entrepreneur, i.e., an entrepreneur who decided to enter and become the manager-cumowner of a firm, obtains a utility below her reservation utility $\bar{u}$. In this sense, no active entrepreneur has an incentive to exit. Moreover, the number of firms in the reached subgame is such that if one more firm had entered, then the resulting equilibrium utility in that subgame would have fallen below $\bar{u}$. In this sense, no passive

\footnotetext{
${ }^{8}$ In the limit case $n \rightarrow \infty$ of perfect competition, all weight is given to the unit cost: the market price then equals the unit (or marginal) production cost.

${ }^{9} \mathrm{It}$ is presumed here that consumers' welfare is decreasing in the market price $p$.
} 
entrepreneur has an incentive to enter. Since the number of participating firms is here treated as a real, rather than integer, variable, the equilibrium utility to all entrepreneurs, active and passive alike, is exactly $\bar{u}$ : a single equation replaces two inequalities. The subsequent analysis concerns only symmetric equilibria in the product market, and it is assumed in this subsection that the outside option is better than setting up a firm and then running it at zero output (and effort) level: $\bar{u}>\varphi(0)$.

As observed above, managers' equilibrium utility level $v(n, m)$ is continuously and strictly decreasing in $n$. Hence, for any reservation utility level $\bar{u} \in \mathbb{R}$ there exists at most one (real) number $n \geq 1$ of firms such that all entrepreneurs are indifferent between market entry and the outside option. If the reservation utility $\bar{u}$ is too high above a monopolist's utility level - then no such $n$ exists. Likewise, if the reservation utility $\bar{u}$ is too low - below the utility level of a manager of a firm in a perfectly competitive market - then no such $n$ exists. In the first case the number of firms in the market is zero, and in the latter case it is plus infinity. However, the latter case is excluded since in the limit case of infinitely many firms the utility to a manager is at most $\varphi(0)$, a utility level that by assumption is below $\bar{u}$. Formally, let $n^{*}(m)$ denote the equilibrium number of firms under free entry and exit. Then $n^{*}(m)=0$ if $v(1, m)<\bar{u}$, and otherwise $n^{*}(m)$ is the unique solution to the equation

$$
v(n, m)=\bar{u}
$$

Not surprisingly, the number of participating firms under free entry and exit increases with the size $m$ of the market: there exists some minimal market size $m^{\circ}>0$ such that $n^{*}(m)=0$ for $m<m^{\circ}, n^{*}\left(m^{\circ}\right)=1$, and $n^{*}(m)$ is strictly increasing in $m$ for $m>m^{\circ}$. Does this rise in the number of firms, when the market is expanded, induce more or less managerial effort?

This question can be answered by way of the following thought experiment. Imagine that the product market initially is in a symmetric interior Nash equilibrium with $n$ active firms, each producing output quantity $q^{*}$, and each manager exerting effective effort $x^{*}$. Suppose some manager $i$ contemplates alternative effort/output pairs for herself. If she chooses effort/output pair $\left(x_{i}, q_{i}\right)$, while all other firms remain at their equilibrium output level, her firm's profit becomes

$$
\pi_{i}=\left[x_{i}-\frac{n-1}{m} q^{*}-\frac{1}{m} q_{i}\right] q_{i} .
$$

While profit and effort affect her utility directly, her firm's output matters only indirectly to her, via its effect on her firm's profit. Suppose that manager $i$, given any effective effort $x_{i}$ that she contemplates to exert, chooses her firm's output level $q_{i}$ so that her firm's profit is maximized, conditional on her effective effort $x_{i}$ and under 
the hypothesis that the other firms produce their equilibrium output $q^{*}$. It is easily verified (using (6)) that she will then choose

$$
q_{i}=\frac{m}{2} \max \left\{0, x_{i}-\frac{n-1}{n+1} x^{*}\right\} .
$$

As expected, the manager will thus choose a higher output level the more effort she has decided to exert. At low level of effort, her firm's unit cost $c_{i}=1-x_{i}$ is so high that the optimum output level is zero. From the viewpoint of the resulting utility to the manager, we may without loss of generality assume that she considers only effective effort levels $x_{i}$ that exceed $\frac{n-1}{n+1} x^{*}$. Given such choices of effort, and with optimal adaptation of output to effort, the profit to firm $i$ is the following convex increasing function of its manager's effective effort:

$$
\pi_{i}=\frac{m}{4}\left(x_{i}-\frac{n-1}{n+1} x^{*}\right)^{2} .
$$

The graph of this function defines the manager's "possibility frontier" in the $\left(\pi_{i}, x_{i}\right)$-plane. These are the best combinations of profit and effective effort available to the manager when all other managers exert their equilibrium effort. In the same plane we may draw indifference curves for manager $i$. The optimal effective effort for manager $i$ is $x^{*}$, a point of tangency between her possibility frontier and one of these indifference curves. Under free entry this indifference curve is determined by managers' reservation utility, i.e., by the equation $u\left[\pi_{i}, b\left(1-x_{i}\right)\right]=\bar{u}$, see Figure 1 .

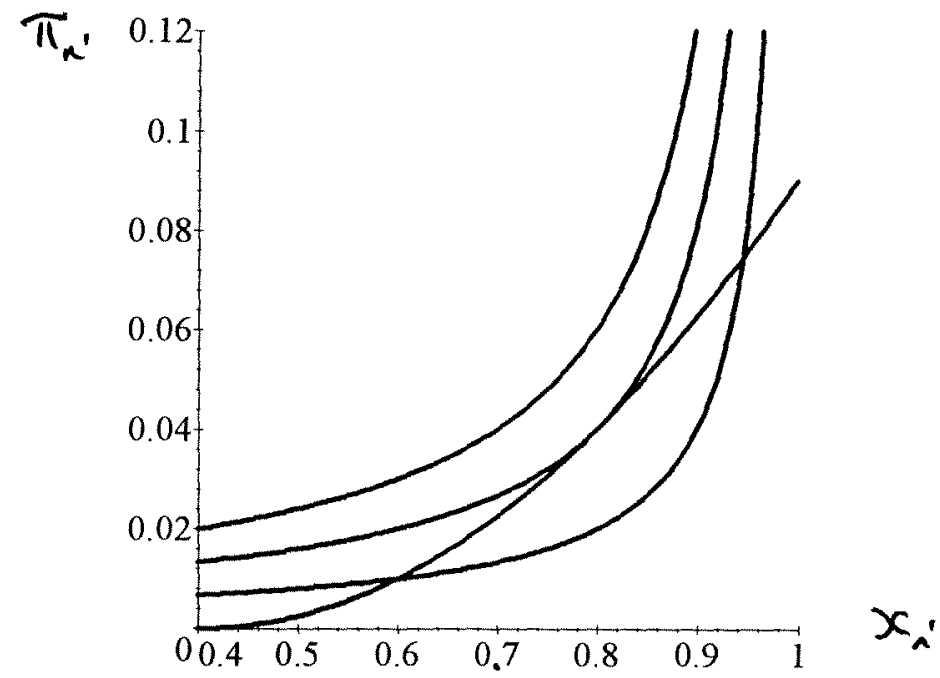

Figure 1: The equilibrium "possibility frontier" of manager i, and three indiffererence curves. (Parametrization as in Section 4 , with $m=\lambda=1$ and $n=3$.) 
Market integration here means an increase in the parameter $m$, accompanied by an increase in the number $n^{*}(m)$ of firms. Assuming that the reservation utility of managers is unaffected, the effect of market integration is that the tangency point with the reservation utility indifference curve may move. Hence, no income effect is here at work, all hinges on the substitution effect. If the tangency point moves as market size changes, then managerial effort and profit necessarily move in the same direction: either both increase or both decrease (in order to keep utility constant). It turns out that both increase. It is as if managers trade "leisure" for "money" when the market expands. Consequently, market integration under free entry and exit enhances the internal efficiency of firms.

Proposition 2. Equilibrium managerial effort under free entry and exit is strictly increasing in market size $m$.

By assumption the utility of all entrepreneurs remains constant under market integration. However, consumers in the product market benefit in two ways. On top of the well known increased "allocative" efficiency gain due to the increased number of participating firms, resulting in a lower market price, managers work harder and so firms operate under lower costs, adding to the downward pressure on the market price. Granted that consumers' welfare is decreasing in the price of the product in question, we conclude that market integration is a Pareto improvement: a welfare gain for consumers and no welfare loss for managers.

Remark: This conclusion rests, inter alia, upon the assumption that managers' reservation utility, $\bar{u}$, is unaffected by the change in market conditions. The qualitative result still holds (by continuity) if $\bar{u}$ increases only slightly. Another presumption is that factor prices (implicit in the definition of the marginal cost) are unaffected.

\section{EXAMPLE}

The above analysis is particularly simple in the special case of a linear relation between managerial effort and unit cost, combined with Cobb-Douglas preferences. Let

$$
c(e) \equiv 1-e
$$

and

$$
u(\pi, e) \equiv \log \pi+\lambda \log (1-e)
$$

for some $\lambda>0 .{ }^{10}$ The residual $z=1-e$ may be interpreted as leisure and $\lambda$ as the intensity in managers' taste for leisure. It is easily verified that conditions (A) and

\footnotetext{
${ }^{10}$ Note that the domain of the subutility function $\varphi$ is here restricted to $\mathbb{R}_{++}$. The domain may be extended to $\mathbb{R}$ by setting $\varphi(\pi)=-\infty$ whenever $\pi \leq 0$, mutatis mutandis.
} 
(B) are met. In this special case effective effort and effort coincide: $x=b(1-e)=$ $1-(1-e)=e$.

4.1. Fixed number of firms. The first-order condition (8) has the explicit solution

$$
e^{*}=x^{*}=\frac{n+1}{n+1+\lambda} .
$$

A striking feature of this equation is that the market size parameter $m$ is absent. Hence, in this special case equilibrium managerial effort, and hence also the internal efficiency of firms, is independent of market size. As expected, the equilibrium effort level is increasing in the number $n$ of firms and decreasing in managers' taste $\lambda$ for leisure. Moreover, as the number of firms tend to infinity, the equilibrium managerial effort approaches its upper bound, 1 , irrespective of managers' taste $\lambda>0$ for leisure. Hence, in the limit of perfect competition even the most leisure-loving managers exert maximal effort.

In contrast to effort and price, output and profit per firm do depend on market size,

$$
q^{*}=\frac{m}{n+1+\lambda} \text { and } \pi^{*}=\frac{m}{(n+1+\lambda)^{2}} .
$$

4.2. Free entry. As expected, the number of firms in the market under free entry is increasing in market size:

$$
n^{*}(m)=\max \left\{1,\left(m \lambda^{\lambda} \exp (-\bar{u})\right)^{\frac{1}{2+\lambda}}-1-\lambda\right\}
$$

Note the concavity of the function $n^{*}$ : market integration results in a reduction of the total number of firms.

Inserting the expression for $n^{*}(m)$ in equation (18), one obtains the following expressions for managerial effort, $e^{* *}(m)$, under free entry and exit:

$$
e^{* *}(m)=1-\left(\frac{\lambda^{2} \exp (\bar{u})}{m}\right)^{\frac{1}{2+\lambda}}
$$

As expected, market integration induces managers to exert more effort.

4.3. Marshall vs. Hicks. If we think of the residual $z_{i}=1-e_{i}$ as the manager's leisure and $\pi_{i}$ as the upper bound on her consumption, then the manager's "budget set" $B(n, m)$ in the leisure/consumption space is obtained from equations (13) and (16): 


$$
\begin{aligned}
B(n, m)= & \left\{\left(z_{i}, \pi_{i}\right): 0<z_{i} \leq \frac{2+\lambda}{n+1+\lambda}, \pi_{i} \leq \frac{m}{4}\left(\frac{2+\lambda}{n+1+\lambda}-z_{i}\right)^{2}\right\} \cup \\
& \cup\left\{\left(z_{i}, \pi_{i}\right): \frac{2+\lambda}{n+1+\lambda}<z_{i} \leq 1, \pi_{i} \leq 0\right\}
\end{aligned}
$$

Figure 2 shows (the interesting part of) this non-convex set, along with a few indifference curves.

First suppose the number $n$ of firms and market size $m$ both are fixed and given. Any change in market conditions, i.e., in these two parameters, results in a shift of the budget set $B(n, m)$, and the effects on managers's demand for leisure - hence supply of managerial effort - can be studied just as in Marshallian demand analysis. The effect on managers' choice of leisure can be decomposed into an "income effect," i.e., a parallel shift of the "budget curve," and a "substitution" effect, i.e., a change in the slope of the "budget curve".

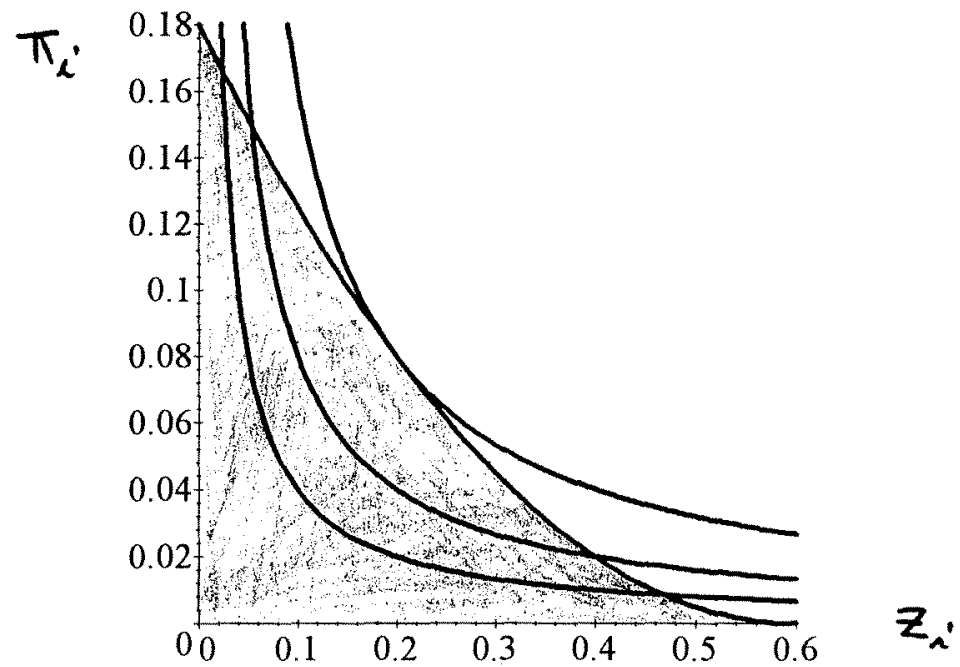

Figure 2: The equilibrium "budget set" of manager $\mathrm{i}$, for $\lambda=1, m=2$, and $n=3$, and three indifference curves.

Second, suppose only market size $m$ is fixed and given, while the number of firms is determined by free entry and exit. Then the effects on managers' choice of leisure 
from a change in market size can be studied in the spirit of the Hicksian compensated demand analysis. For any change in $m$ is fully compensated by entry and exit of firms - so that all managers remain at their initial utility level. What changes is only the "relative price" of leisure as against consumption - here given by the "possibility frontier." Figure 3 shows how this frontier changes as the market size $m$ changes. It is as if market integration induces a higher (here non-linear) "relative price" of leisure.

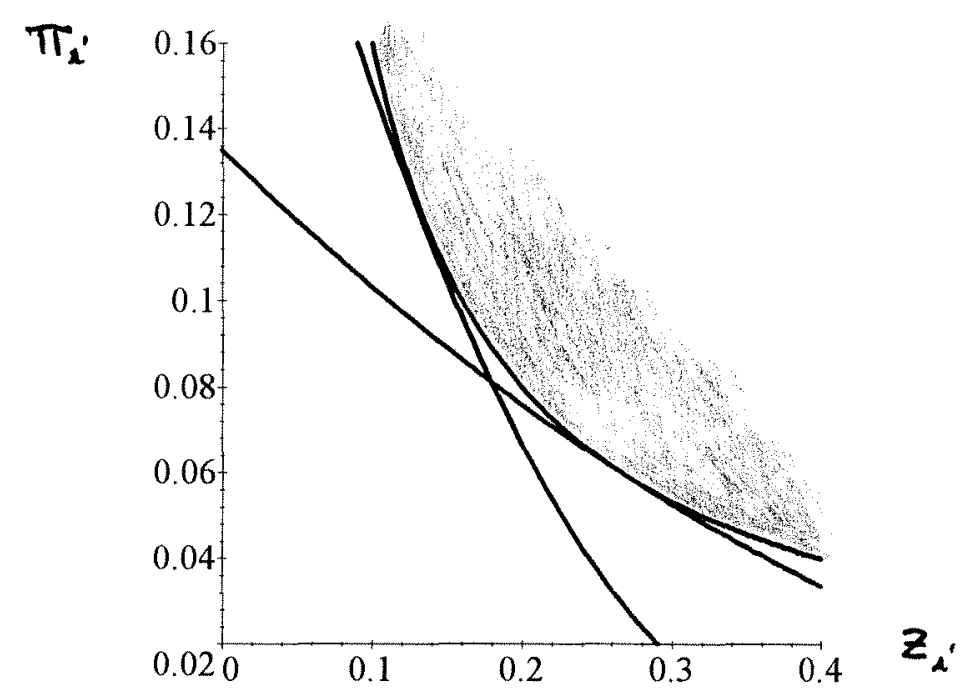

Figure 3: The reservation utility indifference curve, and the "possibility frontier" associated with a small market (the flatter curve), and with a large market (the steeper curve), respectively.

\section{EXTENSIONS AND VARIATIONS}

The above analysis of the question of whether market conditions may influence the internal efficiency of firms internal efficiency was restricted to a particular setting. Hence, a variety of extensions are called for before robust conclusions can be claimed. Here is a list of a few such extensions. First, the present study has been restricted to managerial incentives to cut production costs. Incentives to promote product quality and implement useful technical innovations are highly relevant potential extensions. In such a setting the present description of "entrepreneurs" may be enriched. Second, the present analysis rests upon the heroic assumption that demand is linear. Are the qualitative results valid under more general demand specifications? Third, an important extension of the present model would be to allow for general equilibrium effects, both with respect to factor prices and to managers' outside options. 


\section{REFERENCES}

[1] Corden W.M. (1970), "The efficiency effects of trade and protection", in I.A. McDougall and R.H. Snape (eds), Studies in International Economics, NorthHolland Publ. Co., Amsterdam.

[2] European Commission (1988), "The economics of 1992", European Economy 35.

[3] Hart O. (1983), "The market mechanism as an incentive scheme", Bell Journal of Economics 14, 366-382.

[4] Hayek F.A. (1945), "The use of knowledge in society", American Economic Review $35,519-530$.

[5] Hayek F.A. (1949), "The meaning of competition" in Individualism and Economic Order, Routledge, London.

[6] Hermalin B.E. (1992), "The effects of competition on executive behavior", RAND Journal of Economics 23, 350-365.

[7] Hicks J. (1935), "Annual survey of economic theory: the theory of monopoly", Econometrica 3, 1-20.

[8] Holmström B. (1979), "Moral hazard and observability", Bell Journal of Economics 10, 74-91.

[9] Horn H., S. Lundgren and H. Lang (1995), "Managerial effort incentives, Xinefficiency and international trade", European Economic Review 39, 117-138.

[10] Leibenstein H. (1966), Allocative efficiency versus x-efficiency", American Economic Review 56, 392-415.

[11] Martin J. P. (1978), "X-inefficiency, managerial effort and protection", Economica $45,273-286$.

[12] Martin S.(1993), "Endogenous firm efficiency in a Cournot principal-agent model", Journal of Economic Theory 59, 445-450.

[13] Nalebuff B. and J. Stiglitz (1983), "Information, competition, and markets", American Economic Review 73, 278-283.

[14] Nickell S. (1996), "Competition and corporate performance", Journal of Political Economy 104, 724-746. 
[15] Scharfstein D. (1988), "Product-market competition and managerial slack", RAND Journal of Economics 19, 147-155.

[16] Schmidt K. (1994), "Managerial incentives and product market competition", Bonn University, mimeo.

[17] Smith, A. (1776), An Inquiry into the Nature and Causes of the Wealth of Nations. Citation from edition by R.H. Campbell, A.S. Skinner and W.B. Todd, 1976, Clarendon Press, Oxford.

[18] Vickers J. (1995), "Concepts of competition", Oxford Economic Papers 47, 1-23.

[19] Weibull J. (1996), "Managerial incentives and market integration", Research Institute for Industrial Economics WP 472, Stockholm, Sweden. 